\title{
Social Spirals through Everyday Group Life: Settings and Group Styles in a Comparative Perspective
}

\author{
Sebastiano Citroni* \\ Università degli studi di Milano Bicocca, Milan, Italy
}

Everyday group life is generally neglected in the study of the ongoing shifts affecting voluntary associations. This paper is grounded on a comparative ethnography of three Milanese associations affected by transformations in forms of voluntary participation, repertoires of action, and in their relations with public institutions. The study focuses on group styles and settings to ascertain the role played by everyday group life in shaping the implications of these transformations for the production of inclusive outcomes by the observed associations. The author introduces three different results produced by the studied associations and account for them with the same overall argument, which focus on practices and spaces shaping everyday group life. The main findings illustrate

OPEN ACCESS

Edited by: Andrea Mubi Brighenti, University of Trento, Italy

Reviewed by: Peter Charles Chambers, Deakin University, Australia Raquel Andrade Weiss, Federal University of Rio Grande do Sul (UFRGS), Brazil

*Correspondence: Sebastiano Citroni sebastiano.citroni@unimib.it

Specialty section: This article was submitted to Sociological Theory, a section of the journal Frontiers in Sociology

Received: 17 October 2017 Accepted: 14 December 2017 Published: 08 January 2018

Citation: Citroni S (2018) Social Spirals through Everyday Group Life: Settings and Group Styles in a Comparative Perspective.

Front. Sociol. 2:23. doi: 10.3389/fsoc.2017.00023 that everyday group life works both as a filter through which transformations produce consequences and also as a site of autonomous elaboration through which associations' outcomes are made and unmade.

Keywords: everyday life, group style, setting, voluntary associations, civil society

\section{INTRODUCTION}

The growing segregation of neighborhoods and institutions has resulted in the increased relevance of the study of potentially "urban inclusive settings" (Blokland and Nast, 2014, p. 3). The focus on these settings shifts the study of social exclusion and integration from cities and neighborhoods to everyday organizations, such as churches, colleges, firms, gyms, schools, childcare centers (Small, 2009), and voluntary associations (Dekker and Uslaner, 2001). This latter type of organizations is the subject of high expectations, particularly concerning their capacity to activate social participation and inclusion (Lichterman, 2009). At the same time, empirical studies of voluntary associations produce highly controversial results, with recurrent emphasis on the ambivalent role they may play with respect to wider urban and political transformations in which they are involved (Edmondson, 2001; Kwon, 2004; Tissot, 2014). There is a repeated emphasis on the fact that associations promote diverse "forms of socialities," which "differently open up social connections" (Pink, 2008, p. 179) and may not always lead to social inclusion.

A variety of analyses underline the fact that the development of these outcomes is "shaped by the settings in which contact emerges" (Blokland and Nast, 2014, p. 6; Small, 2009). This study takes seriously the relevance of everyday group life shown by such research and seeks to narrow the analytical focus further. To do this, the study departs from the-widely shared-assumption that each organization has a single relevant corresponding setting and acknowledges the variety of situated settings in which the everyday life of a single organization unfolds (Eliasoph and Lichterman, 2003). Distinctions are made between different types of settings that compose everyday group 
life drawing on previous studies that expand the category of backstage/frontstage (Goffman, 1959), juxtaposing it with other dimensions, such as formal/informal and natural/created for research purposes (Eliasoph, 1996). Among the implications of the adopted theoretical focus, there is the neglect of established categories of social capital such as gender, ethnicity, and race (Dekker and Uslaner, 2001); this is not due their irrelevance, as derives from the intention of highlighting relatively new dimensions, such as group style and settings (Eliasoph and Lichterman, 2003).

This theoretical focus is developed through a comparative ethnography of three associations, which aims to pinpoint the role played by everyday group life in shaping different transformative processes and their implications for the production of inclusive outcomes for the groups involved. The way in which outcomes' inclusiveness was ascertained is discussed in the next section with reference to the Tocquevillian social spiral (Lichterman, 2005). The section that follows develops the conceptual couple of group styles and settings (Eliasoph and Lichterman, 2003) and outlines the way in which these concepts are used in the current study. The paper then introduces the case analyses of transformations in voluntary participation, repertoires of action, and relationships of associations with local public authorities. In each case analysis, the following elements are addressed:

- the transformation and associated hypothesis about its implications;

- the relevance of the voluntary group and the reasons for its selection as a case study;

- the outcomes this group produced and the way it accounted for their production in everyday group life;

- the proposed analysis of how the depicted outcomes were affected by the transformation via everyday group life.

The paper, thanks to the conceptual couple of group style and setting, illustrates how everyday group life plays the double role of filter and site of autonomous elaboration that mediate the way in which the studied shifts produce relevant implications for voluntary associations' outcomes.

\section{Theoretical Approach Social Spirals}

Although the general debate on social inclusion focuses primarily on access to spheres, such as the labor market and the educational system (Moulaert et al., 2005), scholars have also addressed the production of inclusive outcomes by voluntary associations (Lichterman, 2005). In this domain of study, one of the most shared grounds of analysis consists of the Tocquevillian argument about the positive social implications of involvement in voluntary groups (Eliasoph, 1996). For Tocqueville, this is not important because it allows people to increase their social contacts but because these settings trigger the development of "significant social relations," that is to say, relationships whose meanings change over time (Lichterman, 2006, p. 534). While acting together in civic groups, people increase their sense of membership in and responsibility for a larger social world: "the reciprocal action of men one upon another," develop new understandings, and come to redefine the "self-interest as properly understood" (Tocqueville, 1969, p. 515).

Dynamic, changing meanings are central to understanding of how sociality in voluntary groups may become "the source of collective imagination" (Pink, 2008, p. 179). Hardly by chance, they are also at the core of one of the ways in which Tocqueville's argument was operationalized through the metaphor of the social spiral (Lichterman, 2005), which corresponds to volunteers' engagement "within an expansive set of social relations" (Pink, 2008, p. 176). The observation of changing meanings requires that attention be paid to groups' everyday life and to the associative practices through which meanings are reproduced and challenged (Eliasoph and Lichterman, 2003). By using a comparison of meaning-making practices in different settings and occasions of everyday group life, it is possible to ascertain if, and which types, of social spirals develop over time through shifts of social relations' meanings.

Despite the relevance of social spirals for voluntary associations, their ongoing shifts are studied by addressing very specific elements and ignoring their impact on meaning-making practices (Dekker and Uslaner, 2001) and on the development of significant social relationships. This study overcomes this limit by scrutinizing everyday group life in order to specify the implications of three transformative processes of voluntary groups for the inclusiveness of the outcomes that they produce.

\section{Sociability and Group Styles}

Recent urban studies have increasingly stressed the positive impact of networks created within everyday organizations on both poverty reduction and improved living conditions (Marques, 2012; Blokland and Nast, 2014, p. 962; Small, 2009). This finding challenges the previously dominant emphasis in the study of urban exclusion on systemic economic dynamics or individual attributes and behavior (Marques, 2012). However, this study of interactions in everyday life still suffers two important limits.

First, it is generally involved in a "quest for unity" (Crook, 1998, p. 537), in which sociability is deemed to be a unitary whole that is analyzed by tracing different sociability "profiles" (Marques, 2012) according to participants' descriptions in interviews of how they use their networks. This research design does not consider space (Marques, 2012, p. 961) and how different settings may promote different "forms of socialities" (Pink, 2008), accesses, and uses of networks (Blokland and Nast, 2014). The second limitation is related to the fact that the analysis of sociability networks ignores the dimension of meaning-making (Spillman, 2002) which constitutes everyday practices that sustain (or challenge) sociability. Cultural factors are repeatedly mentioned but how they are put to use in everyday life is overlooked (Eliasoph and Lichterman, 2003).

To overcome both of these limits, it is possible to borrow specific hypotheses from studies that investigate the conditions that render everyday life interactions the source of social inclusion. Indeed, the comparative ethnographic study of Small (2009) on city mothers involved in childcare centers shows that inclusive outcomes-particularly the expansion in both size and quality 
of social relations-are associated with three characteristics: (a) stability over time, (b) involvement in shared activities, and (c) cooperative rather than competitive action (Small, 2009, p. 14). Other studies show that these features are enmeshed in institutional practices that are embedded in the variety of settings in which everyday group life unfolds (Eliasoph and Lichterman, 2003). These practices were framed in recent developments of American cultural sociology (Spillman, 2002) as group styles, a particularly useful concept for addressing everyday associative practices (Eliasoph and Lichterman, 2003).

Group styles enjoy an already well-established body of research (Spillman, 2002), in which they are defined as "recurring patterns of interaction" that are part of the larger cultural repertoire of a society (Eliasoph and Lichterman, 2003). They are practices-as "sets of human actions associated with each other in a consistent way" (Schatzki et al., 2001, p. 2)-whose recognized components are group bonds, group boundaries, and speech norms (Eliasoph and Lichterman, 2003, p. 739). Each of these elements puts into practice the group's (implicit) assumptions about-respectively-its relationships (imagined and real) with the wider world, members mutual responsibilities, and appropriate speech (Blokland and Nast, 2014) while in specific group settings. Taken together, group styles and settings show how situated styles of membership, solidarity, and appropriated intervention make everyday group life differently able to sustain the development of social spirals (Lichterman, 2005).

\section{Method}

This study is part of a wider research project that focused on the changes experienced by voluntary associations in Milan. The first part of the project identified three dimensions in which major changes in the studied associations occurred: forms of voluntary participation, repertoires of action, and relationships with local public institutions (Citroni, 2014). This is not an exhaustive list of the transformations affecting Milanese associations but they constitute three broad domains in which, according to the observed associations, the shifts that most affected their organizational stability, efficacy, and survival (Braunstein et al., 2014) were concentrated.

In the second part of the research project, 34 exploratory interviews were carried out to select an urban area in which to focus the comparative ethnography of three case studies. The ethnography aimed to scrutinize how changes took shape in everyday group life and their implications for the inclusivity of the associations' outcomes. Negotiating the access to the field as volunteer with the associations' managing boards, the cases were identified within the semi-peripheral Milanese neighborhood of Via Padova: a mixed zone in terms of class and ethnic composition, with an immigrant population ranging from $20 \%$ to more than $50 \%$ and characterized by a historical presence of a variety of local associations (Arrigoni, 2011, p. 27). The chosen associations had different organizational forms but shared two elements that made them, instead of other ones, particularly suitable for a comparative study: (a) they were embedded in the same urban context and shared the goal of enhancement of local social inclusion with particular, but not exclusive, attention being paid to the integration of foreign and most marginalized citizens; (b) each association was either experiencing or had recently experienced circumstances that allowed for a focus on one of the three domains of transformation outlined above. A period of at least 7 months of "theory-driven participant-observation" (Lichterman, 2002) of everyday group life and public initiatives was dedicated to each case. ${ }^{1}$ The analytical purpose was to specify if the social relations promoted by the observed associations changed their meanings over time and how this might be affected by the transformation processes in which each group was involved. This required the researcher's "participant sensing" (Duffy et al., 2011, p. 20) presence in everyday group life and the use of the "body as an instrument of research" (Longhurst et al., 2008), as illustrated in the next three sections. ${ }^{2}$

\section{New Forms of Voluntary Participation}

Contemporary changes in socioeconomic conditions impact upon forms of involvementinvoluntary associations (McCulloch, 2014). Diachronic studies documents new types of engagements (Ion, 1997; Wuthnow, 2002), which vary among themselves but consistently contribute to the spread of ephemeral or "plug-in" forms of volunteering (Lichterman, 2005). In Italy, the debate on changes in forms of voluntary participation documents new, emerging forms of participation, in which individual involvement in single organizations is less stable and more sporadic (Ranci, 2006). Given that according to Small's hypothesis the stability of interactions is a necessary condition for the development of a positive social spiral, it is worth analyzing more closely how such a change takes shape in everyday group life and what implications it entails for the development of significant social relationships.

The case study chosen for this analysis is Dolmen, a voluntary organization composed by roughly 20 volunteers, founded in 1994 by a group of teachers and parents of pupils of an elementary school, which aimed to promote local social inclusion by enhancing the social function and educational role of the school in a period of increasing cuts to public resources in education. The group was formally lead by a managing board composed by nine members, even if many decision-making processes took place informally, involving also other activists. In 2010, the association abruptly increased its visibility at the city level and this was accompanied by an increase in initiatives dedicated to the general public (and not just those involved in the school) promoted by new associates and volunteers, recruited from outside the traditional channels tied to the local elementary school. In 2010, 11 new volunteers started to participate pro-actively in formal occasions of associative life, thus lowering the average age of association's volunteers by 19 years. New associates engaged

${ }^{1}$ The field research was carried out in different stages, for an overall period that lasted 2 years. In each case, the associations were informed about the research I carried out, and a final seminar was held in order to share with the associations the main research results. No specific resistance was met to the presence of the researcher in the field as volunteer helping to carry out a variety of activities.

${ }^{2}$ For this research, an ethics approval was not required as per the guidelines of the Sociology and Social Research Department of Bicocca University of Milan; informed and written consent was obtained from all research participants and the ethics procedures proposed by the author were approved by prof. Biorcio, scientific supervisor for this research. 
in associative life through "plug-in volunteering" (Lichterman, 2005), offering the possibility of studying if and how this new type of engagement affected the social spiral promoted by this association.

\section{A Negative Social Spiral}

The newcomers significantly increased the association's internal diversity, thus constituting a potential source of benefits but also challenges for the stability of associative bonds (Braunstein et al., 2014). At the outset, the increased diversity appeared to be beneficial as the association's founding group was aging and newcomers offered the possibility of continuity over time. However, challenges soon arose in the form of repeated frictions, misunderstandings and quarrels in everyday group life. In all of the explorative interviews conducted at the beginning of the empirical research, associates and volunteers reported that the newcomers' presence had provoked a tense atmosphere inside the association. Unprompted, three interviewees explicitly associated the newcomers' presence with the beginning of the "ongoing progressive deterioration of associative bonds and group cohesion."

Participant observation allowed a first-hand experience of this deterioration as it developed through polemic e-mail exchanges, whispered malicious comments, systematic absences in specific initiatives, angry outbursts, mutual insults, tears and slammed doors during meetings, all of which provoked perceivable generalized anxiety and distress. Most volunteers and associates, particularly the women, complained to the researcher in backstage settings of everyday group life about the difficulties they experienced in taking part in meetings that increasingly unfolded in such a tense atmosphere. During the 7 months of the empirical research, 8 of the 16 members of the managing board left, including the association's president. Long-standing partnership relations with external parties-such as that of the association with the elementary school-were spoiled by increasing reciprocal suspicion. Furthermore, four friendships and intimate relationships among long-standing associates ended due to conflicts concerning different debates that arose in everyday group life, such as participation in public calls or the use of associative funds for different initiatives. These outcomes suggest that Dolmen developed a negative social spiral: the meanings of the relationships promoted by the association changed over time but in the opposite direction to those described by Tocqueville.

The newcomers were considered, even by themselves, to be ultimately responsible for this outcome. Their presence prompted the emergence of an internal fracture that separated associates who aimed to restore the original mission of the association (pure voluntary activities in support of the school) from those in pursuit of the transformation of the association into a social enterprise delivering professional services. The idea that this divergence had caused the crisis of internal solidarity and long-standing external relationships was consistent with the argument that changes in the original mandate of a nonprofit group inevitably has a negative impact on the solidarity of its members (Horch, 1994). Furthermore, Small (2009) would account for this result with reference to the fact that the entrance of new participants promoted competitive, instead of cooperative, interactions, which undermined the possibility of producing social inclusion. However, both hypotheses fail to explain how the conflict over the association's mission (prompted by new participants) produced the observed negative social spiral, neither do they specify the role of everyday life in the development of this outcome.

\section{Analysis}

In order to develop an account from within (Pink, 2012, p. 4), sensations and emotions experienced by the researcher while participating in everyday group life must be taken analytically seriously. These elements were effectively depicted by an associate's intervention during a formal meetings of group life:

Lately, even now, when participating to this meeting I have the constant sensation of walking on eggshells... which also systematically break! with a sense of crumbling ground beneath the feet that is difficult for me to stand on...we had some quarrels also in the past but not in this way

These images are effective in evoking the dramatic perceptions that surged during arguments in which fundamental, allegedly shared, assumptions-such as to the relationship with the elementary school, the definition of the associative mission and the association's very survival-were questioned. During the attempt to investigate the situated ground that supported associative bonds and the interactions that contributed to its disintegration, it was observed that sensations of instability and crumbling ground did not develop in all occasions of association's everyday life. Instead, they were setting-specific and surged uniquely in interactions taking shape in settings characterized by the presence of two specific group styles. A close examination of their functioning allows an understanding of how the new volunteers were associated with the outcome of negative social spiral through the filtering role of everyday group life.

The first group style constituted the recurrent way through which Dolmen related to one of the most long-standing assumption about collective action in Europe: "the majority of Europeans see associations as weapons of war, ready to be tested on the battlefield. An association is an army, in which you talk to count and animate yourselves for marching against the enemy" (Tocqueville, 1969 , p. 202).

This implicit understanding emerged in the most formal settings of everyday life - the managing board and associates' meetings - through a style of associative militancy. In the setting where this style prevailed, the loyalty to the cause of the association was the ground on which situated group bonds developed:

Newcomer: Why don't we really engage into a participatory process to redefine the mission of the association? I already discussed the idea with some of you ...

Longstanding member [interrumpting]: I realize that it is not clear that this association is not a nursery for ideas! This a place where things are done [raising his voice], we have a list of things to do that is already long! 
New: I didn't mean to provoke the argument in this way, it is just that we were discussing it this morning at the bar, you were also there and you seemed to agree, I don't see why now you react like that!

The newcomer took up and developed an idea that had been discussed that very same morning in the researcher's presence, while drinking coffee at the bar. In this informal setting such a discussion was permissible, but during a formal meeting it questioned the ground on which group bonds were defined (the loyalty to the cause), prompting the attack/defensive intervention of the other participant and thus nurturing the above-cited process of "deterioration of associative bonds." In other formal occasions of group life, newcomers expressed similar seemingly "inappropriate" interventions that called forth that collective feeling of crumbling earth beneath the feet.

The second recurrent pattern of interaction derived from the assumption, promoted in Italy during the 1970s by the "new volunteering" movement (Ranci, 2006), that volunteering is a channel of democratic participation when it directly and autonomously tackles social needs that would be otherwise unsatisfied (Melucci, 1996, p. 169). This assumption took shape in everyday associative life through a pro-active citizenship style that territorialized those settings in which specific initiatives were carried out and prepared, such as Dolmen's school for foreigners and its children's workshops. In these occasions, new participants' seemingly inappropriate interventions rendered explicit the ground on which situated definitions of group bonds, group boundaries and speech norms developed:

Newcomer: given that we volunteers, we cannot carry on all the organizing tasks, what if we enroll professionals to do the work for us?

Longstanding participant: are we joking!? If this is where we're going to, you can go on without me ... my own engagement as free citizen is what makes sense here!

The pro-active engagement "as free citizen" is not one of many means by which the group's associative goals were pursued; instead, it defines the group boundaries, characterizing the group's situated identity in specific occasions of everyday group life. In these settings, publicly raising the possibility of delegating volunteers' work to professionals is not an acceptable option, given that it openly questions the implicit understanding that sustains group boundaries. The interventions of newcomers, when not taken as gaffes that were embarrassedly ignored, accelerated the deterioration of associative bonds because they cracked the situated definition of group's boundaries and solidarity among members. In particular, this occurred when newcomers' interventions brought into question direct engagement in the everyday group settings where a pro-active citizenship style prevailed and when they challenged to the loyalty to associative cause in the case of an associative militancy style.

The observed outcome of a negative social spiral did not derive directly from shifts in forms of voluntary participation or from the ongoing redefinition of the associative mission; instead, it was tied to the way in which these shifts took shape in the everyday group life through the above outlined group styles. The diversity of newcomers did not represent a menace in itself, but their presence became problematic in those settings where they-generally inadvertently-questioned the implicit meanings that sustained the situated definition of solidarity among group members.

\section{New Repertoires of Associative Action}

Among the most relevant of the current shifts affecting voluntary associations in Italy, is the spread of new, highly symbolic initiatives such as cultural and convivial events (Melucci, 1996, p. 183). These initiatives nurture the internationally recognized growth of "civic events" (Sampson et al., 2005) that has prompted an increasingly polarized debate about the implications of this new repertoire of action. This debate features, on the one hand, enthusiastic claims about events' potential for regenerating civil society and social participation (Sampson et al., 2005) and, on the other, skeptics' dismissive framing of the matter in terms of using "barbecues to counteract social exclusion and enhance public life" (Mathews, 2001, p. 138). In any case, little attention has been devoted to the study of how events' implications develop through everyday group life according to constraints and possibilities of such a complex and variegated domain.

This study develops this analysis with a case study focused on Triba, a voluntary association-founded in 2009 and lead by a five-member managing board-that organized a week long "neighborhood festival" made of roughly 100 small events, in six locations within the observed neighborhood. The association's participants were roughly 40 activists and consisted of both single citizens and of other local associations. The general aim of this initiative was illustrated by the association's president during the 2013 press conference as follows:

[to] enhance social cohesion and integration in the neighborhood through occasions of exchange and sociality [...] [to] encourage people to be pro-actively involved in taking care of the neighborhood, using events to address local social needs.

Two particular features made Triba a suitable case for studying how events affected the inclusivity of associations' outcomes via everyday group life. First, among the variety of local associations of the neighborhood (Arrigoni, 2011, p. 30), this was the only one that pursued a goal of social inclusion through the exclusive use of events. Second, it offered the possibility of studying a variety of locations and everyday settings in which events took shape, with a focus on differences in their content and types of unfolding.

\section{A Partial Social Spiral}

In everyday group life, Triba acknowledged the fact that not all of its events succeeded in reaching the association's ambitious goals. Associates and volunteers grouped events on the basis of the six locations in which they took place and assigned different locations different efficacy in the realization of the association's aims. This efficacy was discussed in terms of "local projectuality," a feature unanimously identified in the events developed just in 
two locations out of six. After the monthly meeting, while walking together toward home, a volunteer noted that:

local projectuality [...] is doing things really bottomup, listening closely the needs of local residents and also involving them, but with respect, to organize events that meet such needs. Otherwise, you just do top-down initiative

"Local projectuality" constituted a way of "doing things" that specified the social spiral pursued by Triba as it succeeded in turning the meanings of relations between citizens and the public sphere from one of complaints and demands to pro-active engagement and community activism. Given that, according to Triba's own viewpoint, "local projectuality" developed in two locations out of six, the general outcome of this case can be framed in terms of the activation of a partial social spiral. This partiality shows that hypotheses - such as those of Sampson et al. (2005) or Mathews (2001) — that associate specific outcomes with events as a unitary repertoire of action, are not able to fully account for the development of social processes that are much more varied and nuanced. In order to overcome this limit, this study further develops the focus on everyday life, beginning with an analysis of how the association accounted for the outcomes that it produced in informal everyday group settings.

Indeed, this process of accounting for outcomes did not openly develop in occasions of group life, such as meetings and managing boards. Instead, it emerged in backstage settings, such as the lunch the researcher shared with the association's president in a location that was removed from the association's venue and thus from the possibility of being overheard by other members of the association:

I think you have already realized it: the associations that set up events in the neighborhood festival are all firstly interested in themselves. They put all their energy into the competition for visibility.... this makes citizens' participation hard to develop, citizens participation develops in spite of citizens' associations not thanks to them as they say...

This account resonates with Small's hypothesis that competing (rather than cooperative) interactions are negatively associated with the possibility of producing social inclusion. Visibility benefits associated with events (Vitale, 2007) would make this repertoire of action ineffective for the pursuit of goals of social inclusion. Nevertheless, this factor is not able to analytically account for the development of "local projectuality" in two locations. To address this limit a more thorough view of how events developed through everyday group life is required, with a particular focus on differences among various everyday settings in which they unfolded.

\section{Analysis}

The observant-participation in everyday group life allowed the researcher to specify what distinguished the development of events that-in everyday group life-were associated (or not) with "local projectuality."

Different ways of developing events were correlated with recurrent features that were embedded into two different group styles, as illustrated in the above Table 1. Each group style was associated with specific settings of everyday group life, endowing them with conditions that differed in their capacity to sustain the development of "local projectuality." The argument can be illustrated with reference to the criteria through which appropriate interventions (Blokland and Nast, 2014) were defined in different settings.

In those settings where the assembly-performative style was enacted, the intervention was a direct contribution to events' development. This was also the case for the following criticism developed during a monthly public meeting about one of the festival's six locations:

Volunteer: We should relate more directly with the public administration, [...] to carry on political battles on issues concerning migrants, we need to be more political to address such issues

President: Ok! Good, however, I invite both you and anyone who has something concrete to propose, to do it! [unusually raising his voice] The point here is about improving things! You make proposals then we vote on them and go forward; or, if you think we are completely wrong, why don't you enter the managing board!? I'm happy to give you my role! [embarrassed silence following]

As with any other intervention, in this setting criticisms were accepted if they directly contributed to the organization of events through specific proposals. In the excerpt the president's-seemingly out of place-reaction signals the violation of the pattern that generally confined criticisms that

TABLE 1 | Different events' development.

\begin{tabular}{|c|c|c|}
\hline Local projectuality & No & Yes \\
\hline Type of settings in which events were set up & Public, openly accessible (libraries, bars) & Private and informal (living rooms, associations' venues) \\
\hline Meetings' implicit shared meaning & Meeting as means (to be end by 11:30 p.m.) & Meeting as goal in itself (without scheduled end time) \\
\hline Collective interactions & $\begin{array}{l}\text { Strictly regulated by formal procedures (agenda, list of } \\
\text { interventions, formal decision-making processes) }\end{array}$ & $\begin{array}{l}\text { Grounded on participants' expressivity, according to } \\
\text { developments not planned in advance }\end{array}$ \\
\hline Appropriate intervention (speech norm) & Oriented to give a direct contribution to events' developments & It is straightforward and it contributes to the conviviality \\
\hline Group style & Assembly performative & Expressive-sociality \\
\hline
\end{tabular}


did not encompass direct solutions to backstage settings. This definition of the appropriate intervention made it particularly difficult to publicly discuss issues that were only tangentially relevant to specific proposals but were integral to group's efficacy, such as the above-cited problem of the competing quest for visibility by groups involved in the festival. Hardly, by chance, according to the group's own viewpoint, "local projectuality" did not develop in any of the events that took place in the location referred to in the last excerpt. This lack of "local projectuality" was also tied to other aspects that were equally embedded in the speech norms and group style that sustained exchanges in the everyday settings where events developed. For example, speaking publicly in these settings was done by creating a "list of interventions," which required the ability to formulate and postpone interventions until an appropriate time. Moreover, proposals for events required the completion of a form and its delivery within a scheduled deadline. The strict adherence to these formal procedures constituted a relevant access barrier to the participation of citizens-especially for foreigners with little knowledge of the Italian language - and made the development of "local projectuality" unlikely.

Other events developed through everyday settings characterized by different group styles and related speech norms, with similar relevant implications for the inclusivity of the associations' outcomes. Associates and volunteers assigned "local projectuality" to events that took shape in settings where recurrently an expressive-sociality group style prevailed. Here, speech norms did not restrict the expression of criticism to specific proposals; instead any intervention seemed to be appreciated, especially if contributed to the conviviality of the occasion. The "obligation of not obligating" () functioned as ultimate speech norms, visible through the awkward reactions to its violations, such as in the following excerpt from ethnographic notes of a monthly meeting:

Ukrainian woman: We should make a larger party, using also the spaces in the streets, otherwise you do not even know that there is something going on, instead in the streets everyone sees.

Italian husband: I'm sorry, my wife has not got it right: the event is in the courtyard of our building! You cannot do it in the road! [shaking his head] excuse her...

[seconds of embarrassed, very unusual, silence]

Older Italian woman: but it's a great idea! We can try to do something in the road this year... maybe not all the event but some things...

A jarring note was perceptible on this and on a small number of other occasions in which there was an attempt to censor an intervention. Such interactions are significant for indicating relevant speech norms. This recurrent pattern had significant implications for the outcomes the events produced while they developed through everyday group life. Here, the "obligation of not obligating" made it easier to publicly develop criticisms and to involve foreign residents in comparison to the assembly performative group style.

Looking closely at the different implications of the two outlined group styles allows a fresh analysis of the above-cited "backstage observation" that citizens' involvement occurred in spite of associations' presence, rather than as a result of it. Indeed, the analysis of group styles reveals that this was not just due to the egoistic attitude of associations but it emerged out of the recurring patterns through which groups communicated internally and with external parties in the different settings of everyday group life. The outlined group styles were unequally able to sustain the development of "local projectuality" and thus the social spiral pursued by this association.

\section{New Relationships with Public Institutions}

There is an international body of literature that underlines that ongoing shifts in local welfare systems are among the main axes along which voluntary associations are changing (Sampson et al., 2005). In Italy, the decline of public resources has changed the traditional dependence relationships that for many years tied associations to public institutions (Ranci, 2006). New public-private tools, such as co-planning programs and calls from community foundations, are increasingly common in Milan (). These changes are accompanied by a rhetoric that argues that the survival and success of voluntary associations depends upon their capacity to borrow rationales and procedures from business organizations (Vitale, 2007). As a result, new tasks and procedures are overloading voluntary associations and threatening their capacity to effectively pursue their goals of social integration (Ranci, 2015).

The case study chosen for this type of transformation is Mape, a voluntary association founded in 1998, composed by 14 volunteers and whose main activities consisted of Italian courses for foreigners, cultural initiatives (mainly concerts, arts shows, and movie projections) and the promotion of a migrants' committee. Even if a formal managing board existed, the association was lead by its charismatic leader, who ruled the main decisionmaking processes. The purpose of the association is to promote social integration at the local level, with particular reference to the social inclusion of foreign and disadvantaged people. What made Mape an interesting case study was the fact that in the last 3 years its relationships with local public institutions have been significantly changing (Gonigori, 2011), involving a significant reduction of funds, with a parallel increase of private and selffinancing initiatives.

\section{An Effective Social Spiral}

A previous study (Gonigori, 2011) documented that relations inside the committee and the association were initially characterized by two elements: (a) participants experiencing difficulties interacting because of both absence of a shared language and racist national-based prejudices; (b) isolation and distrust of the committee in relation to other groups, particularly those who were most socially stigmatized, such as LGBT and disabled people (ibidem). Over time, while setting up an ethnic parade, internal committee relations developed into ties of solidarity (ibidem), which gradually opened up to the outside world, developing 
cooperative and partnership relationships with other groups. As noted in previous studies, "committee sociality involves its members in becoming situated within an expansive set of social relations" (Pink, 2008, p. 176), allowing in this case the integration of foreigners into wider social networks which they would normally struggle to access (Gonigori, 2011). The researcher's participation in Mape's everyday life allowed for a first-hand experience of the development of the social spiral promoted by this case study. Indeed, the researcher's relationship with the association and committee's members shifted over a period of 7 months from suspicious strangeness, to public familiarity and finally to the development of forms of situated solidarity. Given the initial state of the relations both inside the committee and in the association's everyday life with respect to the researcher's presence, the changes they experienced were particularly impressive and illustrated the capacity of Mape to effectively pursue a social spiral.

According to the observed association, its effectiveness was linked to the flexibility that characterized its way of operating, both internally and with external subjects. Indeed, on public occasions such as during an interview with a journalist from a local newspaper, the association stressed how their most significant outcomes rarely resulted from initiatives that were well planned in advance, as argued by the rhetoric that accompanied the ongoing shifts in the local welfare system (Vitale, 2007). On the contrary, positive results emerged out of what they called a "continuous collective improvisation." The researcher was directly involved with this flexible way of operating during the press conference that was held in 2014 to present the annual ethnic parade. The program of the conference was outlined just half an hour before it started, at which time it was also decided that the researcher would have play the role of conductor. This mode of operation illustrates a recurrent pattern that allowed the association to include unplanned people and resources, valorizing their autonomous contribution in shaping their initiatives.

If the efficacy in pursuing the social spiral appeared to be strictly related to its organizational flexibility, the origin of this recurrent way of "doing things," and its relationships with the shifting welfare conditions in which the association operated, requires further analysis.

\section{Analysis}

It could be argued that this flexible way of operating derived from the fact that the observed association operated in changing and confusing (Ranci, 2006) public-institutional conditions and that this context encouraged organizations' capacity to continuously adapt along the way. However, this argument is refuted by the fact that the other two cases outlined above also operated in the same overall institutional conditions but in different ways and with different results. Furthermore, the association's flexible mode of operation had already been documented in the previous ethnographic study on Mape (Gonigori, 2011) and thus it did not seem to be directly affected by recent changes in relationships with public institutions.

The close examination of the socialities (Pink, 2008) within the association's everyday life revealed that the above-cited metaphor of "collective improvisation"-taken in the musical, technical sense-is particularly adequate to develop further insights. Indeed, just as musical improvisation is not the result of random behavior but follows specific rules and models, in the same way, the observed associative practices emerged out of implicit recurring patterns (Eliasoph and Lichterman, 2003). In particular, in most settings of everyday group life a style of autonomous situated presence channeled collective interactions and shaped the appropriateness of interventions. This style was evident for example in the way in which association's members asked for the researcher's participation and support during the annual ethnic parade:

You will stay in that point, I will also be there and we will see what needs doing along the way, while things happen

Participating in group life required discretion but, at the same time, a readiness to intervene and thus there was a certain elasticity to demands that was difficult to predict in advance. The members of the committee were required not only to participate in general organizational activities but also to respond to demands that arose during the course of group life and events, such as the occasion when, just before the ethnic parade started, the association's president unexpectedly asked a young Filipino volunteer to participate in a national television news interview. As in previous cases, group styles were most evident when they were challenged. For example, during a cigarette break of a meeting the association's president noted that initially the organization of the ethnic parade

was quite a disaster, volunteers and committee's members did not know what to do and they just looked around, constantly asking what needed to be done

This lack of autonomy was inappropriate behavior because it violated one of the implicit assumptions on which group bonds, boundaries, and speech norms were grounded in most settings of everyday group life. The autonomy of members in their relationships inside and outside the group worked as access threshold for volunteers but also as condition of possibility for making situated exchanges expand into a social spiral that could include unplanned for people (as in the above-cited case of the press conference).

Changes in the institutional context in which this case study was embedded mattered in shaping its initiatives and their outcomes. For example, over time, the reduction of public funding forced the organizers to review the program of the ethnic parade, shortening its length (Gonigori, 2011). However, the institutional

TABLE 2 | Summary of the main elements of the proposed argument.

\begin{tabular}{llll}
\hline Tranformations & $\begin{array}{l}\text { Case } \\
\text { study }\end{array}$ & $\begin{array}{l}\text { Social spiral } \\
\text { results }\end{array}$ & Group styles \\
\hline $\begin{array}{l}\text { New forms of voluntary } \\
\text { participation }\end{array}$ & Dolmen & Negative & $\begin{array}{l}\text { Associative militancy } \\
\text { Pro-active citizenship } \\
\text { New repertoire }\end{array}$ \\
$\begin{array}{l}\text { of action } \\
\text { New relations with } \\
\text { public institutions }\end{array}$ & Mape & Partial & $\begin{array}{l}\text { Assembly performative } \\
\text { Expressive sociality } \\
\text { Autonomous situated } \\
\text { presence }\end{array}$
\end{tabular}


context mattered for the activated social spiral through group style: even with less public funds at disposal, the development of the pursued social spiral still required participants to become involved in social relations that took shape as situated autonomous presence in most everyday group settings (Table 2 ).

\section{Conclusive Remarks}

The associations taken as case studies produced different outcomes, the inclusiveness of which was syntheticallylabeled in term of negative, partial, and effective social spirals. Transformations in institutional conditions, repertoires of action, and forms of involvement affected the depicted outcomes in each case through two elements-group styles and settings-that embed and are embedded in everyday group life. These elements were used in this study to specify respectively, practices and place, which are at the core of the recent interdisciplinary perspective on everyday life (Pink, 2012). They allowed the researcher's immersion in everyday group life in order to detail the social spirals pursued by the observed groups, the spirals that were actually promoted and to account for gaps between goals and outcomes. To the detriment of the use of established research categories such as gender, ethnicity, and race (Dekker and Uslaner, 2001), the proposed analysis allowed to outline how group styles and settings are associated with different analytical roles. Indeed, studying group styles by focusing on settings allowed the situating of (Pink, 2012) associative practices, confirming that "in the shaping of sociability, space still makes a difference" (Marques, 2012, 29). Settings reveal the double movement through which this "difference" operates, given that they are both bounded spaces within which we engage in practices and places that we constitute with our practices. Furthermore, the mutually constitutive relationship between settings and group styles has not hindered the observation that while group styles tend to reproduce institutionalized ways of understanding the world, settings may innovate such routinized understanding

\section{REFERENCES}

Arrigoni, P. (2011). Terre di nessuno. Come nasce la paura metropolitana. Milano: Melampo.

Blokland, T., and Nast, J. (2014). Social mix revisited: neighborhood institutions as setting for boundary work and social capital. Sociology 48, 482-499. doi:10.1177/0038038513500108

Braunstein, R., Fulton, B., and Wood, R. (2014). The role of bridging cultural practices in racially and socioeconomically diverse civic organizations. Am. Sociol. Rev. 79, 705-725. doi:10.1177/0003122414538966

Citroni, S. (2014). Associazioni a Milano. Bisogni e mappatura del volotnariato. Milano: Franco Angeli.

Crook, S. (1998). Minotaurs and other monsters: everyday life in recent social theory. Sociology 32, 523-540. doi:10.1017/S0038038598000078

Dekker, P., and Uslaner, E. (2001). Social Capital and Participation in Everyday Life. London: Taylor \& Francis Ltd.

Duffy, M., Waitt, G., Murray, A., and Gibson, C. (2011). Bodily rhythms: corporeal capacities to engage with festival spaces. Emot. Space Soc. 4, 17-24. doi:10.1016/j. emospa.2010.03.004

Edmondson, R. (2001). "Studying civic culture ethnographically and what it tells us about social capital. Communities in the west of Ireland," in Social Capital and Participation in Everyday Life, eds P. Dekker and E. M. Uslaner (New York: Routledge), 59-72. through-never predictable-combinations of the variety of components that define places as events (Massey, 2005). In this study, this was particularly evident through gaffes in which the shared understandings supporting the associative practices were made explicit in the very moment in which they were questioned.

When combined for analytical purposes, group styles and settings highlight the double role played by everyday group life in mediating between the investigated transformations and the detected outcomes of social spirals: (a) filter through which general changes take specific shape and (b) site of autonomous elaboration for the possible development of significant, changing, social relationships. The depiction of these roles allows a reframing and overcoming of the dualism through which everyday life practices are generally conceived of: as passively reproducing general structures or as innovative and path-breaking elements (Pink, 2012). This finding also confirms the argument that the division between ordinary life as mundane and activism as public makes less and less sense (Pink, 2012, 5), most particularly when considering group styles as forms of everyday solidarity, unequally sustaining the development of social spirals.

\section{ETHICS STATEMENT}

For this research, an ethics approval was not required as per the guidelines of the Sociology and Social Research Department of Bicocca University of Milan and as per national regulations; informed and written consent was obtained from all research participants and the ethics procedures proposed by the author were approved by Prof. Biorcio, scientific supervisor for this research.

\section{AUTHOR CONTRIBUTIONS}

The author confirms being the sole contributor of this work and approved it for publication.

Eliasoph, N. (1996). Making a fragile public: a talk-centered study of citizenship and power. Sociol. Theory 14, 262-289. doi:10.2307/3045389

Eliasoph, N., and Lichterman, P. (2003). Culture in interaction. Am. J. Sociol. 108, 735-794. doi:10.1086/367920

Goffman, E. (1959). The Presentation of Self in Everyday life. New York: Doubleday.

Gonigori, E. (2011). Il 'comitato stranieri' di via Padova. Tesi di Laurea, Università degli Studi di Milano-Bicocca, Milan.

Horch, H. (1994). On the socio-economics of voluntary organizations. Voluntas. Int. J. Volunt. Nonprofit Organ. 5, 219-230. doi:10.1007/BF02353987

Ion, J. (1997). La fin des militants? Paris: Editions de l'Atelier.

Kwon, H. (2004). Associations, civic norms, and democracy: revisiting the Italian case. Theory Soc. 33, 135-166. doi:10.1023/B:RYSO.0000023423.34384.88

Lichterman, P. (2002). "Seeing structure happen: theory-driven participant observation," in Methods of Social Movement Research, eds S. Staggenborg and B. Klandermans (Minneapolis: University of Minnesota Press), 118-145.

Lichterman, P. (2005). Elusive Togetherness: Church Groups Trying to Bridge America's Divisions. Princeton: Princeton University Press.

Lichterman, P. (2006). Social capital or group style? Rescuing tocqueville's insights on civic engagement. Theor. Soc. 35, 529-63. doi:10.1007/s11186-006-9017-6

Lichterman, P. (2009). Social capacity and the styles of group life: some inconvenient wellsprings of democracy. Am. Behav. Sci. 52, 846-866. doi:10.1177/ 0002764208327662 
Longhurst, R., Ho, E., and Johnston, L. (2008). Using 'the body' as an 'instrument of research'. Area 40, 208-217. doi:10.1111/j.1475-4762.2008.00805.x

Marques, E. (2012). Social networks, segregation and poverty in Sao Paolo. Int. J. Urban Reg. Res. 36, 958-979. doi:10.1111/j.1468-2427.2012.01143.x

Massey, D. (2005). For Space. London: SAGE.

Mathews, D. (2001). "Can public life be regenerated?" in Measuring the Impact of Nonprofit Sector, eds P. Flynn and V. Hodgkinson (New York: Kluwer Academic/Plenum), 137-156.

McCulloch, A. (2014). Cohort variations in the membership of voluntary associations in Great Britain, 1991-2007. Sociology 48, 167-185. doi:10.1177/ 0038038513481643

Melucci, A. (1996). Challenging codes. Collective action in the information age. Cambridge: Cambridge University Press.

Moulaert, F., Martinelli, F., Swyngedouw, E., and Gonzales, S. (2005). Towards alternative model(s) of local innovation. Urban Stud. 42, 1969-1990. doi:10.1080/00420980500279893

Pink, S. (2008). Re-thinking contemporary activism: from community to emplaced sociality. Ethnos. J. Anthropol. 73, 163-188. doi:10.1080/00141840802180355

Pink, S. (2012). Situating Everyday Life: Practices and Places. London: SAGE.

Ranci, C. (2006). Il volontariato. Bologna: Il Mulino.

Ranci, C. (2015). The long-term evolution of the government third sector partnership in Italy: old wine in new bottle? Voluntas 26, 2311-2329. doi:10.1007/ s11266-015-9650-7

Sampson, R., MacIndoe, H., McAdam, D., and Weffer-Elizondon, S. (2005). Civil society reconsidered: the durable nature and community structure of collective civic action. Am. J. Sociol. 111, 673-714. doi:10.1086/497351
Schatzki, T., Knorr-Cetina, K., and von Savigny, E. (2001). The Practice Turn in Contemporary Theory. London: Routledge.

Small, M. (2009). Unanticipated Gains. Origins of Network Inequality in Everyday Life. Oxford: Oxford University Press.

Spillman, L. (2002). Cultural Sociology. London: Blackwell Readers.

Tissot, S. (2014). Loving diversity/controlling diversity: exploring the ambivalent mobilization of upper-middle-class gentrifiers, South End, Boston. Int. J. Eur. Regional Stud. 38, 1183-1196. doi:10.1111/1468-2427. 12128

Tocqueville, A. (1969). Democracy in America. New York: Doubleday.

Vitale, T. (2007). In nome di chi? Partecipazione e rappresentanza nelle mobilitazioni locali. Milano: Franco Angeli.

Wuthnow, R. (2002). Loose Connections: Joining Together in Americas Fragmented Communities. Harvard: Harvard University Press.

Conflict of Interest Statement: The author declares that the research was conducted in the absence of any commercial or financial relationships that could be construed as a potential conflict of interest.

Copyright $\odot 2018$ Citroni. This is an open-access article distributed under the terms of the Creative Commons Attribution License (CC BY). The use, distribution or reproduction in other forums is permitted, provided the original author(s) or licensor are credited and that the original publication in this journal is cited, in accordance with accepted academic practice. No use, distribution or reproduction is permitted which does not comply with these terms. 